\title{
Expression profiling of the CHS8, CHI1A, IFS2, and CHR genes in black soybean seed [Glycine max (L). Merr.] of F4 generation
}

\author{
Dadang Sumardi ${ }^{1,}{ }^{*}$, Aulia Marwah Mumtaza ${ }^{1}$, Rijanti Rahaju Maulani ${ }^{1}$, Adi Pancoro ${ }^{1}$, Husna Nugrahapraja ${ }^{1}$, Sony \\ Suhandono $^{1}$, Tati Suryati Syamsudin ${ }^{1}$, and Agung Karuniawan ${ }^{2}$ \\ ${ }^{1}$ School of Life Sciences and Technology, Institut Teknologi Bandung, Jalan Ganesa 10, Bandung 40132, Indonesia \\ ${ }^{2}$ Faculty of Agriculture of Universitas Padjadjaran, Jalan Raya Bandung-Sumedang KM 21, Jatinangor Sumedang 45363, Indonesia \\ ${ }^{*}$ Corresponding author: dadangsu@sith.itb.ac.id
}

SUBMITTED 1 July 2019 REVISED 23 August 2019 ACCEPTED 17 December 2019

\begin{abstract}
Black soybean [Glycine max (L.) Merr.] produces isoflavones as secondary metabolites, which have many benefits for human health and plant defense system. Expression profiling can guide potential work in functional genomics of the isoflavone biosynthesis pathway. Previous studies showed the vital role of the CHS8, CHI1A, and IFS2 genes in isoflavone biosynthesis. However, expression profiling of these genes in the local black soybean varieties is still limited. This study investigated the gene expression levels of the CHS8, CHIA, IFS2, and CHR genes in local varieties, namely, UP106 (high isoflavone) and UP122 (low isoflavone) and its progenies, i.e., UP106xUP122 and UP122xUP106. Relative gene expression profiling was conducted on the basis of Reverse Transcriptase Polymerase Chain Reaction (RT-PCR) with ACT2/7 as a housekeeping gene. As a result, the expression level of CHS8 in UP122 was lower than that in UP106. No significant difference in the expression level of CHI1A was observed in all samples. The expression levels of CHS8 and CHIA in both progenies were higher than that in the parental line, whereas the expression levels of IFS2 in both progenies were lower than that in the parental line. CHS8 and IFS2 expression from UP106xUP122 was higher than that from UP122xUP106, whereas CHI1A expression from UP122xUP106 was higher than that from UP106xUP122. CHR showed a high expression in the reciprocal cross; however, this expression did not exceed from UP106. In conclusion, the crossing between parental lines did not affect the gene expression level in the isoflavone biosynthesis pathway.
\end{abstract}

KEYWORDS black soybeans; isoflavone; local varieties; biosynthesis pathway; reverse transcriptase PCR

\section{Introduction}

Black soybeans contain carbohydrates, lipids, and a high protein content, which reaches approximately 70\%, as well as vitamins and minerals (Dajanta et al. 2013; Lam et al. 2010). In Indonesia, black soybeans have contributed significantly to the food industry, e.g., as the raw material for the soy sauce industry. In various countries, such as China, Japan, and Korea, black soybeans have also been used as a drug for hundreds of years to detox, prevent inflammation, and improve the quality of red blood cells (Xu and Chang 2008).

Black soybeans are known as a plant that has isoflavone levels 100 times higher than other legumes (Xu and Chang 2008). Isoflavones have an essential role in the defense system against biotic and abiotic stresses and in the process of forming root nodules as a result of the interaction between soybean plants and microbes (Akada et al. 1993; Christie et al. 1996). In fact, isoflavones provide many benefits for human health, such as reducing the risk of cardiovascular disease, osteoporosis, menopausal disorders, and cancer (Dhaubhadel 2011; Dixon 2004).

Many researchers have investigated the isoflavone biosynthesis pathway, which is constructed by a variety of enzymatic reactions. The enzymes involved in isoflavone biosynthesis are genetically encoded through the transcription and translation processes. Isoflavonoids are synthesized through the phenylpropanoid pathway. The precursor of the synthesis is L-phenylalanine. First, the amine group of L-phenylalanine is released. Then, cinnamic acid is produced through the Phenylalanine Ammonia-Lyase (PAL) enzyme activity. In the subsequent phase reaction, cinnamate 4-hydroxylase and 4-coumarate CoA ligase convert cinnamic acid into p-coumaroyl CoA (Dhaubhadel 2011). Previous studies showed that CHR, CHI1A, and IFS2 are genes that play an important role in isoflavone biosynthesis (Yu et al. 2003). CHR and CHI1A are specific genes that are only found in legume plants. $C H R$ gene expression plays a role in determining the composition ratio of isoflavones (daidzein/genistein/glycitein). Increased gene expression of $\mathrm{CHR}$ can increase the produc- 
tion of the isoflavone daidzein (Yu et al. 2003). CHI1A expression plays an important role in the synthesis of type II chalcone isomerase that functions at the branching point between the production of flavonoids and isoflavonoids. IFS gene is one of the key genes in the synthesis of isoflavones. Previous research showed that the insertion of soybean IFS gene into nonlegume crops successfully alter the metabolism of nonlegume crops to produce the isoflavones genistein and daidzein (Jung et al. 2000).

The expression of genes related to the synthesis of isoflavones provides important information on the process of metabolic engineering of isoflavone in plants. However, information on gene expression profiles is still limited because the expression of isoflavone genes is strongly influenced by cultivar and geographical environment (Cheng et al. 2016). Thus, to manipulate the metabolism of isoflavones in Indonesian black soybean, research on the expression of genes related to the synthesis of isoflavones in black soybean needs to be conducted. The expression profiles of genes related to the synthesis of isoflavones can be used to determine the function of genomic information in the isoflavone biosynthesis pathway (Dhaubhadel et al. 2007). This research was conducted to analyze the gene expression profiles of $C H S$, CHR, CHI1A, and IFS2 in the seeds of two local varieties of black soybeans (i.e., UP106 and UP122) and its crossbreeding result at the F4 generation using Reverse Transcriptase-Polymerase Chain Reaction (RT-PCR).

\section{Materials and Methods}

\subsection{Plant and seed samples}

The black soybean (Glycine max L. Merr) seeds used were local varieties, i.e., UP106 and UP122 obtained from the Laboratory of Plant Breeding, Faculty of Agriculture, Padjadjaran University (through Dr. Agung Karuniawan) and eight F4 genotypes as crossbreeding result. Plants were grown in the area of Tanjungsari, Sumedang (864 m above sea level) in February 2019. Pods were harvested when the plant has reached the R5 phase because isoflavone accumulation in soybeans occurs during the seed maturation stage (Dhaubhadel 2011). Pods were collected, cleaned, and drained, wrapped using aluminum foil with the label, frozen in liquid nitrogen, and stored in $-80^{\circ} \mathrm{C}$.

\subsection{Phenotypic measurement}

In this study, phenotypic variables were measured and used as supporting data. The phenotypic variables included plant height, number of branches, number of pods per plant, number of seeds per plant, the weight of seeds per plant, and the weight of 100 grains.

\subsection{RNA isolation and quantitative and qualitative analyses}

Total RNA samples of black soybean seeds were isolated following the protocol of GeneJET Plant RNA Purification Mini Kit (Thermo Fisher Scientific ${ }^{\mathrm{TM}}$ ). RNA was an- alyzed using electrophoresis and spectrophotometry to determine the quality and quantity.

\section{4. cDNA synthesis}

Approximately one $\mu \mathrm{g}$ of RNA was used for cDNA synthesis following the protocol of GoScript ${ }^{\mathrm{TM}}$ Reverse Transcriptase (Promega Corporation).

\subsection{Reverse transcriptase $P C R$ and data analysis}

The primer sequences used for CHS8, CHI1A, IFS2, and CHR were obtained from a previous study (GutierrezGonzalez et al. 2010), with ACT2/7 as a housekeeping gene. The cDNA samples were amplified using the PCR reagent of the DreamTaq Green PCR Master Mix Kit (Thermo Fisher Scientific ${ }^{\mathrm{TM}}$ ) and the DNA engine thermal cycler Veriti ${ }^{\mathrm{TM}}$ 96-Well Thermal Cycler (Thermo Fisher Scientific $\left.{ }^{\mathrm{TM}}\right)$. PCR mixtures were prepared using $1 \mu \mathrm{L}$ cDNA, $0.5 \mu \mathrm{L}$ forward and reverse primers, $5 \mu \mathrm{L}$ DreamTaq Green PCR Master Mix, and up to $10 \mu \mathrm{L}$ nucleasefree water. PCR products were visualized in $2 \%$ agarose gel stained with FloroSafe DNA Stain. Electrophoresis products were visualized by the Gel Doc ${ }^{\mathrm{TM}} \mathrm{EZ}$ Imager. The thickness of the bands obtained from agarose gel electrophoresis visualization was semiquantitatively analyzed using the ImageJ software (Sheffield 2008). Then, the expression values were tested using one-way analysis of variance $(F 3,8, p<0.001)$ with IBM SPSS20 software.

\section{Results and Discussion}

\subsection{Phenotypic profile}

Parental lines and their offspring showed variations in phenotypic profiles, except for plant height. In terms of plant height, all lines were nearly the same (Figure 3). However, the F4(122x106)e strain was higher than the two parental lines.

Variations in phenotypic profiles (Figure 1 and 2) can be observed from the numbers of pods and seeds per plant (Figure 4), seed weight per plant, and weight of 100 seeds (Figure 5). The two parental strains showed nearly the same numbers of pods and seeds per plant. The cross line generation showed higher numbers of pods and seeds per plant than the two parental lines, except for the F4(122x106)e line. Variations in seed weight per plant and weight of 100 seeds were observed among the lines. The cross line generation showed heavier seed weight per plant and weight of 100 seeds than the two parental lines, except for the F4(122x106)e line.

Based on the yield character, most of the offspring generations showed better yield than the two parental lines. This finding indicates that the yield character exhibited transgressive segregation. The F4(122x106)e line showed the best yield. 


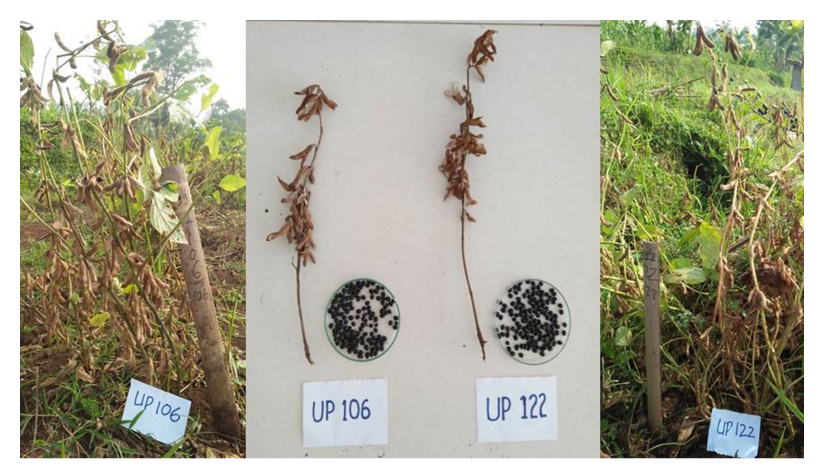

FIGURE 1 Phenotypic profile of parental lines (UP106 and UP122).

\subsection{Genes expression profile}

\subsubsection{Relative expression of $\mathrm{CHS} 8$ gene}

The total relative gene expression shown in Figure 6 indicated that the four samples affected the relative gene expression level of CHS8 (p-value < 0.05). UP106xUP122 and UP122xUP106 exhibited significant differences in CHS8 relative gene expression in the isoflavone biosynthesis pathway. The CHS gene was expressed higher at the initial development stage of the seed, i.e., during the R5 phase, than that at the other stages (Fritze et al. 1991). The results showed a difference in the relative gene expression level of CHS in the four samples because of the differences in the enhancer elements of the CHS gene promoter, which could increase gene expression. Transcription factors that bind to different enhancer elements produced different CHS gene expression levels (Fritze et al. 1991).

\subsubsection{Relative expression of $\mathrm{CHI} A \mathrm{~A}$ gene}

The CHI1A gene expression level was not significant in the four samples ( $p$-value $>0.05$ ). The highest expression levels were exhibited by UP106xUP122, UP106, UP122xUP106, and UP122. UP106xUP122 and UP122xUP106 did not exhibit a significant difference; thus, the reciprocal F4 generation had the same potential in expressing the CHI1A gene. Consistent with the findings of Gutierrez-Gonzalez et al. (2010), we observed that CHI1A gene expression was not significant in the four samples. Moreover, the CHI1A gene showed stable expression levels during the generative growth phases, i.e., R5-R7, indicating that $\mathrm{CHI}$ ensures the stable synthesis of liquiritigenin and naringenin in all four genotypes.

\subsubsection{Relative expression of IFS2 gene}

IFS2 showed differential expression in the four samples (p-value < 0.05). The IFS2 gene expression levels exhibited by UP106xUP122 and UP122xUP106 were higher than those by the two parents. Thus, both UP106xUP122 and UP122xUP106 crosses exhibited significant differences, which, in this case, the group of tillers resulting from the crossing of UP106xUP122 had a higher poten-

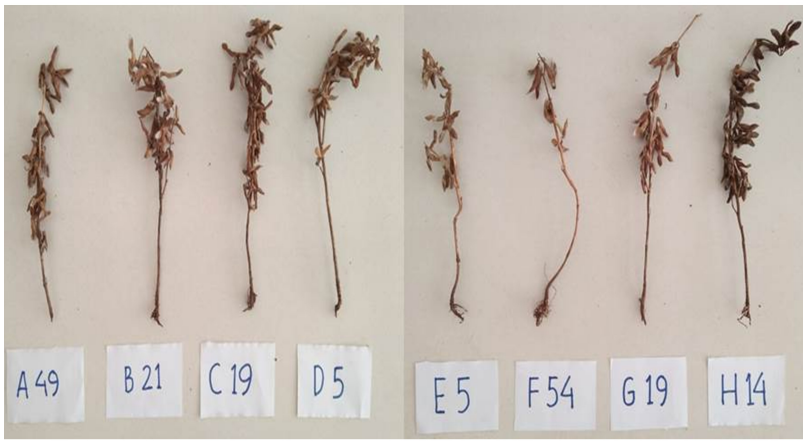

FIGURE 2 Phenotypic profile of offspring lines ((A49-B21 = F4(106x122)a; C19-D5 = F4(106x122)b; E5-F54 = F4(122×106)d; G19-H14 = F4(122×106)e).

tial level of relative gene expression than the group of offspring resulting from the crossing of UP122xUP106.

\subsubsection{Relative expression of $\mathrm{CHR}$ gene}

CHR showed the highest ratio in UP106, UP106xUP122, UP122xUP106, and UP122. The ratios in UP106xUP122 and UP122xUP106 were higher than that in UP122 but did not exceed that in UP106. The crossing of UP106xUP122 and UP122xUP106 had a significant effect (p-value < 0.05) on the CHR gene expression level. Moreover, UP106xUP122 had a higher potential level of relative gene expression than the reciprocal UP122xUP106.

Particularly for legume plants, the chalcone reductase enzyme encoded by the CHR gene is needed for the production of chalcone isoliquiritigenin. The CHR enzyme will compete with the CHI enzyme as a determinant of the relative changes in total genistein and daidzein formed by the division of the intermediate pathway from genistein to the branch of daidzein through increased CHR activity (Gutierrez-Gonzalez et al. 2010).

\subsubsection{Summary of Genes Expression Profile}

The overall profile of relative gene expression in CHS8, CHI1A, IFS2, and CHR showed a positive correlation between parents and its F4 generation. The F4 generation UP106xUP122 has a higher potential for gene expression than its reciprocal because UP106 that acts as the female parent in the cross has a higher potential for gene expression than UP122. By contrast, the F4 generation UP1226xUP106 has a lower potential for gene expression than its reciprocal because UP122 that acts as the female parent in the cross has a lower potential for gene expression than UP106.

Genetic variation formed in the F4 generation, resulted from the crossing UP106xUP122, was caused by genetic recombination between the parents. Genetic recombination is the exchange of genetic material between individuals reproduced sexually that produce recombinant offspring in segregation generation. Genetic recombination occurs through a cellular process during meiosis known as crossing over (Acquaah 2012). 
100

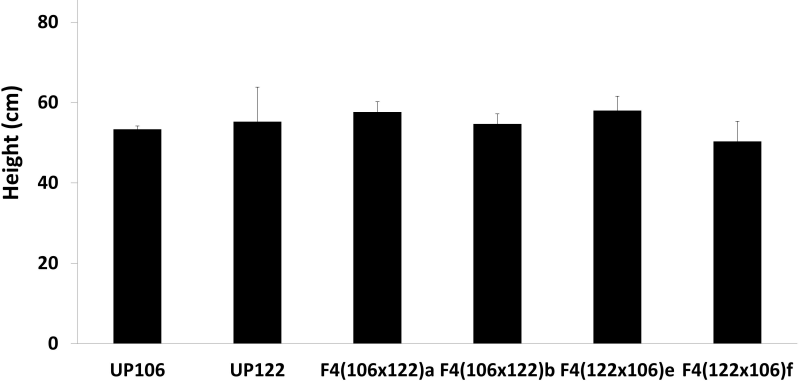

FIGURE 3 Plant height of black soybean of parental lines (UP106 and UP122) and cross lines (F4(106×122)a; F4(106×122)b; F4(122x106)e; F4(122x106)f). Bars showed the height in $\mathrm{cm}$ with triplicates measurement and standar deviation.

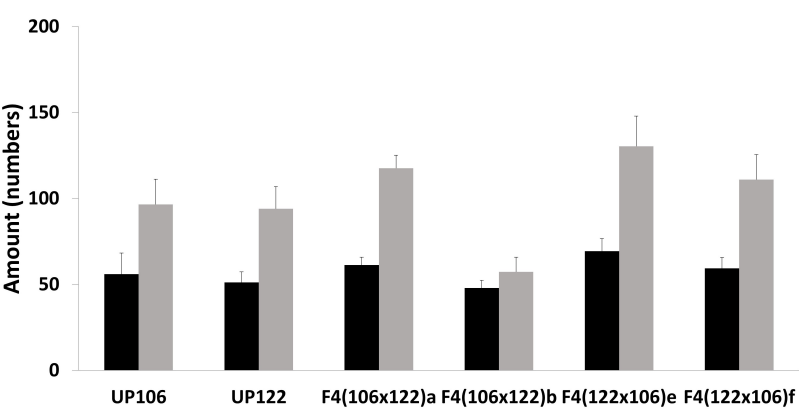

FIGURE 4 Pod (Black Bar) and seed (Grey Bar) numbers per plant of parental (UP106 and UP122) and crossing lines (F4(106×122)a;

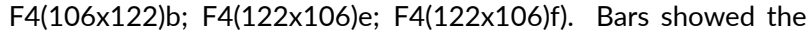
triplicates measurement and standar deviation.

Crossing over is the exchange of genetic material between homologous chromosomes that produce recombinant chromosomes in sexual reproduction, and this event is one of the final stages of genetic recombination that occurs in the pachytene prophase I stage of meiosis in synaptic processes. When chromosomal crossover occurs, homologous chromosomes pair up with each other and exchange segments of their respective genetic material to form recombinant chromosomes. Chromosomal crossover is an essential part of the normal chromosome segregation process that occurs during meiosis (Snustad and Simmons 2012).

The F4 generation has a complex and diverse mix of traits. Variations in cytoplasmic genomes can affect the yield character of the F4 generation phenotype (Park et al. 2006; Zeyl et al. 2005). Genetic variations in the cytoplasm and nucleus affect the interactions that control genetic variation in the F4 generation, which is the result of different combinations of its parents, i.e., UP106xUP122 and its reciprocal UP122xUP106 (Juenger et al. 2010; McKay et al. 2003). According to Chiari et al. (2006), the effect of variations in the cytoplasm needs to be considered in inheritance studies because it will affect the contribution of parental lines to their offspring. Six types of isoflavones show the presence of cytoplasmic effects (Chiari et al. 2006).

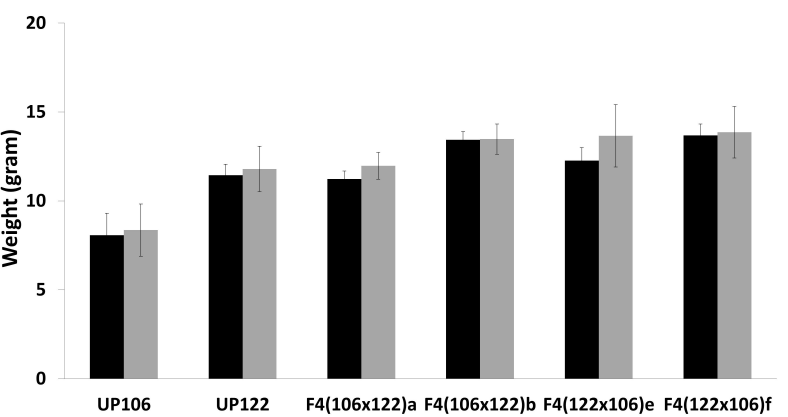

FIGURE 5 Seed weight per plant (Black bar) and weight of 100 seeds (Grey bar) of parental (UP106 and UP122) and crossing lines

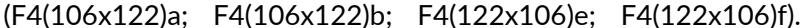
Bars showed the triplicates measurement and standar deviation.

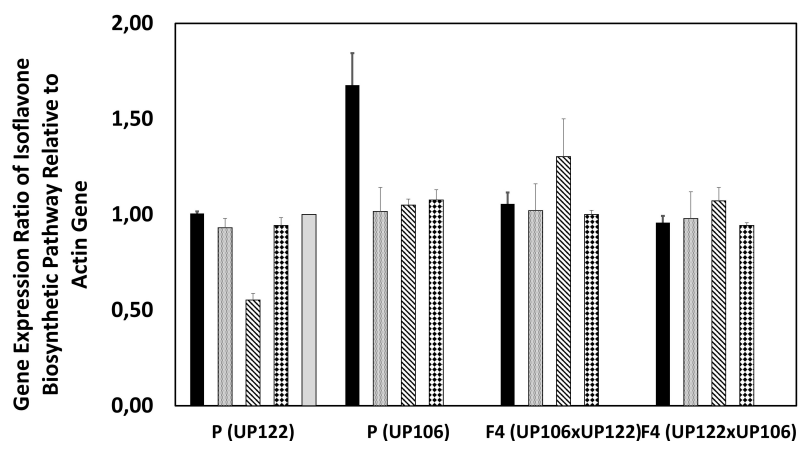

FIGURE 6 Relative Expression Value based on Semi-quantitative Analysis of Reverse Transcriptase PCR. Genes are CHS8 (Black Bar), CHI1A (Dotted Bar), IFS2 (Stripes Bar), CHR (Diamond Bar), F6H3 (Grey Bar), respectively. Bars showed the triplicates measurement and standar deviation.

Each genotype group produces different gene expression levels in CHS8, CHI1A, IFS2, CHR, and F6H3, (Figure 6). Differential expression can be attributed to the regulation of gene expression at the transcription level of each genotype. Cheng et al. (2016) showed that the genotypes were the most critical factors in determining the form and content of isoflavones. Each genotype has a different genetic variation (polymorphism) because of the presence of single-nucleotide polymorphisms (SNPs) that distinguish the genetic information of one individual from that of another individual. SNPs have an influence on the gene expression level (Stranger et al. 2007; Veyrieras et al. 2008). SNPs on the alleles of each genotype will cause an allelespecific expression, in which two alleles are different or more genes are expressed at different levels. Mutations cause changes in the regulatory element (there is at least one regulator mutation) that appears in cis-acting regions (Marioni et al. 2008). Transcriptional regulatory elements in cis-acting regions contain recognition sites where transcription factors attach as trans-acting elements, which enhance or suppress transcription (Maston et al. 2006).

\section{Conclusions}

In conclusion, CHS8, CHI1A, and IFS2 showed differential expression in the parental lines and reciprocal F4 
hybrids. UP106 (high isoflavone) showed higher expression of CHS8 than UP122 (low isoflavone). By contrast, UP122 (low isoflavone) showed higher expression of IFS2 than UP106 (high isoflavone). The crossing between parental lines did not affect the gene expression level.

\section{Acknowledgments}

The authors thank the Ministry of Research Technology and Higher Education through Research Grant PDUPT Scheme No. 002/SP2H/PTNBH/DRPM/2019.

\section{Authors' contributions}

DS, AMM, and HN designed the study. DS and AMM carried out the laboratory work. DS, AMM, HN, and SS analyzed the data. DS, AMM, HN, SS, TSS, AP, and AK wrote the manuscript. All authors read and approved the final version of the manuscript.

\section{Competing interests}

The authors declare no competing interest.

\section{References}

Acquaah G. 2012. Principles of Plant Genetics and Breeding. $2^{\text {nd }}$ Ed. Malden: Blackwell Publishing.

Akada S, Kung SD, Dube SK. 1993. Nucleotide sequence and putative regulatory elements of a nodule-development-specific member of the soybean (Glycine max) chalcone synthase multigene family, Gmchs 7. Plant Physiol. 102(1):321-323. doi:10.1104/pp.102.1.321.

Cheng B, Furtado A, Smyth HE, Henry RJ. 2016. Influence of genotype and environment on coffee quality. Trends Food Sci Technol. 57:20-30. doi:10.1016/j.tifs.2016.09.003.

Chiari L, Koshy Naoe L, Piovesan ND, Chamel José I, Damião Cruz C, Alves Moreira M, Gonçalves De Barros E. 2006. Inheritance of isoflavone contents in soybean seeds. Euphytica. 150(1-2):141-147. doi:10.1007/s10681-006-9102-y.

Christie JM, Jenkins GI, Christie JM, Jenkins GI. 1996. Distinct UV-B and UV-A/blue light signal transduction pathways induce chalcone synthase gene expression in Arabidopsis cells. Plant Cell 8(9):1555-1567. doi:10.2307/3870250.

Dajanta K, Janpum P, Leksing W. 2013. Antioxidant capacities, total phenolics and flavonoids in black and yellow soybeans fermented by Bacillus subtilis: A comparative study of Thai fermented soybeans (thua nao). Int Food Res J. 20(6):3125-3132.

Dhaubhadel S. 2011. Regulation of Isoflavonoid Biosynthesis in Soybean Seeds. In: TB Ng, editor, Soybean - Biochemistry, Chemistry and Physiology. Canada: IntechOpen. p. 243-358. doi:10.5772/15120.
Dhaubhadel S, Gijzen M, Moy P, Farhangkhoee M. 2007. Transcriptome analysis reveals a critical role of CHS7 and CHS8 genes for isoflavonoid synthesis in soybean seeds. Plant Physiol. 143(1):326-338. doi:10.1104/pp.106.086306.

Dixon RA. $2004 . \quad$ Phytoestrogens. Annu Rev Plant Biol. 55:225-261. doi:10.1146/annurev.arplant.55.031903.141729.

Fritze K, Staiger D, Czaja I, Walden R, Schell J, Wing D. 1991. Developmental and UV light regulation of the snapdragon chalcone synthase promoter. Plant Cell 3(9):893-905. doi:10.1105/tpc.3.9.893.

Gutierrez-Gonzalez JJ, Guttikonda SK, Tran LSP, Aldrich DL, Zhong R, Yu O, Nguyen HT, Sleper DA. 2010. Differential expression of isoflavone biosynthetic genes in soybean during water deficits. Plant Cell Physiol. 51(6):936-948. doi:10.1093/pcp/pcq065.

Juenger TE, Sen S, Bray E, Stahl E, Wayne T, Mckay J, Richards JH. 2010. Exploring genetic and expression differences between physiologically extreme ecotypes: Comparative genomic hybridization and gene expression studies of Kas-1 and Tsu-1 accessions of Arabidopsis thaliana. Plant, Cell Environ. 33(8):1268-1284. doi:10.1111/j.13653040.2010.02146.x.

Jung W, Yu O, Lau SMC, O’Keefe DP, Odell J, F G, McGonigle B. 2000. Identification and expression of isoflavone synthase, the key enzyme for biosynthesis of isoflavones in legumes. Nat Biotechnol. 18(2):208-212. doi:10.1038/72671.

Lam HM, Xu X, Liu X, Chen W, Yang G, Wong FL, Li MW, He W, Qin N, Wang B, et al. 2010. Resequencing of 31 wild and cultivated soybean genomes identifies patterns of genetic diversity and selection. Nat Genet. 42(12):1053-1059. doi:10.1038/ng.715.

Marioni JC, Mason CE, Mane SM, Stephens M, Gilad Y. 2008. RNA-seq: An assessment of technical reproducibility and comparison with gene expression arrays. Genome Res. 18(9):1509-1517. doi:10.1101/gr.079558.108.

Maston GA, Evans SK, Green MR. 2006. Transcriptional Regulatory Elements in the Human Genome. Annu Rev Genomics Hum Genet. 7:29-59. doi:10.1146/annurev.genom.7.080505.115623.

McKay JK, Richards JH, Mitchell-Olds T. 2003. Genetics of drought adaptation in Arabidopsis thaliana: I. Pleiotropy contributes to genetic correlations among ecological traits. Mol Ecol. 12(5):1137-1151. doi:10.1046/j.1365-294X.2003.01833.x.

Park HB, Jacobsson L, Wahlberg P, Siegel PB, Andersson L. 2006. QTL analysis of body composition and metabolic traits in an intercross between chicken lines divergently selected for growth. Physiol Genomics. 25(2):216-223. doi:10.1152/physiolgenomics.00113.2005.

Sheffield JB. 2008. An Introduction to ImageJ: A Useful Tool for Biological Image Processing and Analysis. Microscopy and Microanalysis doi:DOI: 
10.1017/S1431927608088752.

Snustad DP, Simmons MJ. 2012. Principles of Genetics. $6^{\text {th }}$ Ed. Chichester: John Wiley \& Sons.

Stranger BE, Nica AC, Forrest MS, Dimas A, Bird CP, Beazley C, Ingle CE, Dunning M, Flicek P, Koller D, et al. 2007. Population genomics of human gene expression. Nat Genet. 39(10):1217-1224. doi:10.1038/ng2142.

Veyrieras JB, Kudaravalli S, Kim SY, Dermitzakis ET, Gilad Y, Stephens M, Pritchard JK. 2008. Highresolution mapping of expression-QTLs yields insight into human gene regulation. PLoS Genet. 4(10):e1000214. doi:10.1371/journal.pgen.1000214.

Xu B, Chang SKC. 2008. Antioxidant capacity of seed coat, dehulled bean, and whole black soybeans in relation to their distributions of total phenolics, phenolic acids, anthocyanins, and isoflavones. J Agric Food Chem. 56(18):8365-8373. doi:10.1021/jf801196d.

Yu O, Shi J, Hession AO, Maxwell CA, McGonigle B, Odell JT. 2003. Metabolic engineering to increase isoflavone biosynthesis in soybean seed. Phytochemistry 63(7):753-763. doi:10.1016/S00319422(03)00345-5.

Zeyl C, Andreson B, Weninck E. 2005. Nuclearmitochondrial epistasis for fitness in Saccharomyces cerevisiae. Evolution. 59(4):910-914. doi:10.1111/j.0014-3820.2005.tb01764.x. 